\title{
Describing variations and taxonomic status of earthworms collected from selected areas in Misamis Oriental, Philippines using principal component and parsimony analysis
}

\author{
Dennis A. Apuan ${ }^{1}$, Mark Anthony J. Torres ${ }^{2}$ and Cesar G. Demayo ${ }^{2}$ \\ 1- Department of Agricultural Sciences, College of Agriculture \\ Xavier University. Cagayan de Oro City, Philippines \\ 2- Department of Biological Sciences, College of Science and Mathematics, \\ MSU-Iligan Institute of Technology, Iligan City, Philippines \\ Correspondence: cgdemayo@gmail.com
}

\begin{abstract}
The present study describes variations and determines the taxonomic status of the collected earthworms from selected areas in Misamis Oriental and Cagayan de Oro city. Principal component and parsimony analyses were used to describe variations and groupings in collected earthworm individuals. Of the five groups of earthworms determined and described, one group was found to be allochthonous and anthropochorous. Cladistic analysis yielded a strict consensus tree with a length of 253 steps, consistency index $=50$ and retention index $=69$. Four groups were identified to belong to Family Megascolecidae, and one group to Family Eudrilidae. Differences observed were attributed to the number and pattern of genital markings, prostomium type, and the number and location of spermathecae. None of the four new megascolecid groups completely match with the nearest genera of Oriental megascolecids. The results of the study clearly indicate the existence of the five new species of earthworms.
\end{abstract}

Keywords: taxonomy, allochthonous, anthropochorous, cladistic.

\section{INTRODUCTION}

Earthworms are ubiquitous and are found in various places in urban and sub-urban areas, some are pests, others are alternate host and carrier of disease and the rest are beneficial that their identity must be known for full utilization of their potentials or possible intervention to alleviate the damage they caused. Out of the 5,500 described species of earthworms worldwide, Philippines had contributed 48 species from 9 genera namely: Isagorex, Pheretima, Pleionogaster, Amynthas, Dendropheretima, Polypheretima, Metaphire, Archipheretima and Pithemera (Blakemore, 2007). Even though 18 megascolecids were recently added from Mt. Kitanglad in Bukidnon, Philippines (James, 2004), still that number of reported species is relatively small considering the tropical conditions and environmental variability. Only very few earthworm species are described in the Philippines, all of which were collected from remote and mountainous regions, and none in the suburban and urban centers. Moreover, the descriptions and taxonomic key available may not be applicable for identification of earthworms too far from the collection site (James, 2004).

Earthworm identification is especially important when one is doing soil health and productivity assessment, for land rehabilitation, or in searching species for its utilization in composting, feeds, medicine etc. Bouchard et al. (2005) reviewed some issues related to problems associated with the taxonomy of earthworms. They pointed 
out that higher hierarchical taxonomic groupings (e.g. families, orders) possess quite similar ecological traits and provide redundant ecological functions. This means that family level classification may not be helpful. This means therefore that the resolution up to the generic hierarchical level of classification is quite important, which may reveal a new property needed for a more specific correlation.

The conventional practice in discovering the identity of earthworms is through character comparison with the nearest neighbour and relatives where descriptions of diagnostic characters are done (Benham, 1946). This method is tedious and subjective and usually does not take into account inherent intraspecific variation in populations of earthworms. In the present study, principal component analysis and parsimony analysis were used to describe taxonomic groupings of known taxa, groupings of unknown collected specimens, and identify useful characters that separate groups and measure phenotypic distances among groups of taxa of earthworms. Relationships among taxa can be inferred by cladistic approaches similar to studies done in Erigoninae (Miller, 1999).

\section{MATERIALS AND METHODS}

Field Collecting of Earthworms, Morphological Data Collection and Description

A total of 175 earthworms were collected in six different sites in two separate locations: 1) Manresa farm in Cagayan de Oro and 2) Burnay, Gitagum, Misamis Oriental, both are within Northern part of Mindanao, Philippines. The earthworms were collected at a maximum of $30 \mathrm{~cm}$ depth, and then photographs of representative samples were taken prior to immobilization treatment. Field collected earthworm samples were washed with water and fixed in a solution containing $10 \%$ ethanol. The samples were later preserved in formalin.

The preserved field collected samples were washed three times to remove the formalin odour before character examination. There were a total of 60 characters from which descriptions were based (Table 1). Twelve of these characters were based from the key to the "Earthworm Families of the World" (Blakemore, 1994, 2000). Data on morphological features of known earthworms were also collected from published monographs and articles for comparison. These data were then stored in the softwares 'Winclada' for display and editing and transferred to Nona for phylogenetic analyses.

\section{Character and Character States Coding}

Binary characters were ordered and polarized using the character states in the outgroup Acanthodrilidae (Blakemore, 2000 and Beddard, 1912). Characters that are found in the outgroup are considered plesiomorphic in nature (ancestral). For the ordered characters, all plesiomorphic character states were coded with a " 0 " and apomorphic states by " 1 ". For multistate characters in which evolutionary pathways are difficult to deduce, the character states were coded with " 0 " to " $n$ ", where " $n$ " is number of state in an array. Since direction of evolution of these characters are not yet determined, they were treated as unordered to refrain from any hypothesis regarding trends in evolution of those characters (Table 1).

\section{Data Processing and Analyses}

All coded data were processed using Principal Component Analysis (PCA) to explore diversity within and among the populations of earthworms and to determine the total number of possible earthworm taxa in the sites. Parsimony analysis was done to determine the relationships, associations and affinities of the earthworms collected from the sites to the known species described in available monographs and other scientific literature. In the family level analysis, 12 characters were used and 3 
outgroup species belonging to 3 different families were selected for the purpose namely: Microscolex dubius (Fletcher, 1887) (Acanthodrilidae), Octochaetona beatrix (Beddard, 1902) (Octochaetidae) and Eukerria saltensis (Beddard, 1895) (Ocnerodrilidae). Earthworms belonging to the Family Megascolecidae were also included belonging to 7 genera and 37 species.

Table 1. Character states and corresponding codes.

\begin{tabular}{|c|c|}
\hline $\begin{array}{l}\text { COD } \\
\text { E }\end{array}$ & CHARACTER STATES \\
\hline 1 & Possession of prostatic gland: (0) absent; (1) present \\
\hline 2 & $\begin{array}{l}\text { Prostatic gland opening: (0) prostatic pores in xvii and xix, separate from } \\
\text { male pores in xvii (acanthodriline); (1) a pair of prostates, tubular or } \\
\text { racemose, opened to the exterior in xviii together with the sperm ducts } \\
\text { (megascolecine); (2) absence of prostates. }\end{array}$ \\
\hline 3 & $\begin{array}{l}\text { Prostatic gland shape: (0) glandular portion has central lumen on bisection, } \\
\text { either long or short cylinder-like structure (tubular); (1) bunch like or } \\
\text { lobular with characteristic branching that is unrecognizable } \\
\text { macroscopically (racemose); (2) absence of prostates. }\end{array}$ \\
\hline 4 & $\begin{array}{l}\text { Male pore orientation: (0) anterior to segment xvi; (1) posterior to } \\
\text { segment xvi; (2) male pore is not developed or not visible. }\end{array}$ \\
\hline 5 & $\begin{array}{l}\text { Male pore location: (0) male pore located on segment xvii; (1) male } \\
\text { pore located on segment xviii; (2) male pore is not developed or not } \\
\text { visible. }\end{array}$ \\
\hline 6 & $\begin{array}{l}\text { Last heart location: (0) last heart posterior to segment xi; (1) last heart } \\
\text { exactly on segment xi. }\end{array}$ \\
\hline 7 & $\begin{array}{l}\text { Nephridia: (0) single pair of nephridia in each segment, usually large in } \\
\text { size (holoic); (1) small and plenty that are either scattered or } \\
\text { conglomerated along intestine, esophagous or near spermathecae (meroic). } \\
\text { (2) No visible nephridia are construed as meroic. }\end{array}$ \\
\hline 8 & $\begin{array}{l}\text { Setal arrangement: (0) } 8 \text { setae per segment usually in } 4 \text { pairs } \\
\text { (lumbricine); (1) setae numerous and arranged equally around each } \\
\text { segment (perichaetine); (2) setal counts vary in different parts of the } \\
\text { body increasing from } 8 \text { segments anteriorly to }>8 \text { per segment } \\
\text { posteriorly. }\end{array}$ \\
\hline 9 & Pre-testicular spermathecae: (0) present; (1) absent. \\
\hline 10 & $\begin{array}{l}\text { Location of gizzard: (0) gizzard on seg v; (1) gizzard on seg viii; (2) } \\
\text { gizzard on seg x; (3) gizzard on seg ix; (4) gizzard on seg xi; (5) gizzard } \\
\text { on seg vii; (6) gizzard on seg vi; (7) gizzard on seg xx; (8) gizzard on seg } \\
\text { xxv; (9) gizzard on seg xxvii. }\end{array}$ \\
\hline 11 & $\begin{array}{l}\text { Testes: (0) testes occupying segments } \mathrm{x} \text { and } \mathrm{xi} \text { (holandric); (1) testes } \\
\text { occupying only segment xi (metandric); (2) testes occupying only segment } \\
\text { x }\end{array}$ \\
\hline 12 & $\begin{array}{l}\text { X. } \\
\text { Gizzard: }(0) \text { absent; (1) present }\end{array}$ \\
\hline 13 & Intestinal caeca: (0) present; (1) absent. \\
\hline 14 & Copulatory pouches: (0) absent; (1) present. \\
\hline 15 & Setae between male pores: (0) absent; (1) present. \\
\hline 16 & Dorsal pore: (0) absent; (1) present. \\
\hline 17 & Spermathecae: (0) absent; (1) present. \\
\hline 18 & Posteriormost spermathecal pore: (0) paired; (1) unpaired; (2) absent. \\
\hline 19 & $\begin{array}{l}\text { Number of spermathecal pairs: (0) } 2 \text { pairs on opposite line; (1) not visible; } \\
\text { (2) } 1 \text { pair on opposite line; (3) } 3 \text { pairs on opposite line; (4) } 4 \text { pairs on } \\
\text { opposite line; (5) unpaired. }\end{array}$ \\
\hline 20 & $\begin{array}{l}\text { Clitellum origin: (0) origin on segment xii; (1) origin on segment xiii; (2) } \\
\text { origin on segment xiv; (3) origin on segment xvii; (4) origin on segment } \\
\text { xviii; (5) not developed. }\end{array}$ \\
\hline 21 & $\begin{array}{l}\text { Clitellum cover: (0) } 4 \text { segments covered; (1) } 10 \text { segments covered; (2) } 9 \\
\text { segments covered; (3) } 13 \text { segments covered; (4) } 2 \text { segments covered; (5) } \\
\text { not developed; (6) } 3 \text { segments covered; (7) } 5 \text { segments covered; (8) } 6 \\
\text { segments covered. }\end{array}$ \\
\hline
\end{tabular}

\begin{tabular}{|c|c|}
\hline CODE & CHARACTER STATES \\
\hline 22 & Clitellum shape: (0) annular; (1) saddle type; (2) not developed. \\
\hline 23 & Genital markings: (0) absent; (1) present. \\
\hline $\begin{array}{l}24 \\
25\end{array}$ & $\begin{array}{l}\text { Most posterior genital markings: (0) absent; (1) unpaired; (2) paired. } \\
\text { Genital markings anterior to clitellum: (0) absent; (1) unpaired; (2) } \\
\text { paired. }\end{array}$ \\
\hline 26 & $\begin{array}{l}\text { Number of unpaired genital markings (GM): (0) not visible; (1) paired; } \\
\text { (2) single genital marking; (3) } 4 \text { unpaired GM; (4) } 5 \text { unpaired GM; (5) } 2 \\
\text { unpaired GM; (6) } 3 \text { unpaired GM. }\end{array}$ \\
\hline 27 & $\begin{array}{l}\text { Number of paired genital markings (GM): (0) no visible genital } \\
\text { markings; (1) } 2 \text { pairs GM; (2) } 3 \text { pairs GM; (3) } 4 \text { pairs GM; (4) } 5 \text { pairs } \\
\text { GM; (5) } 6 \text { pairs GM; (6) } 8 \text { pairs GM; (7) } 10 \text { pairs GM; (8) unpaired. }\end{array}$ \\
\hline 28 & Female gonopore: (0) absent; (1) present. \\
\hline $\begin{array}{l}29 \\
30\end{array}$ & $\begin{array}{l}\text { Number of female gonopore: (0) not visible; (1) single; (2) paired. } \\
\text { Body pigmentation: (0) pink; (1) dark brown; (2) reddish purple; (3) light } \\
\text { brown }\end{array}$ \\
\hline 31 & Prostonium type: (0) epilobic; (1) tanylobic; (2) zygolobic. \\
\hline 32 & Spermathecal pores on intersegment 4/5: (0) absent; (1) present. \\
\hline 33 & Spermathecal pores on intersegment 5/6: (0) absent; (1) present. \\
\hline 34 & Spermathecal pores on intersegment 6/7: (0) absent; (1) present. \\
\hline 35 & Spermathecal pores on intersegment 7/8: (0) absent; (1) present. \\
\hline 36 & Spermathecal pores on intersegment 8/9: (0) absent; (1) present. \\
\hline 37 & Genital markings on 8: (0) none; (1) paired; (2) unpaired. \\
\hline 38 & Genital markings on 9: (0) none; (1) paired; (2) unpaired. \\
\hline 39 & Genital markings on 10: (0) none; (1) paired; (2) unpaired. \\
\hline 40 & Genital markings on 11: (0) none; (1) paired; (2) unpaired. \\
\hline 41 & Genital markings on 12: (0) none; (1) paired; (2) unpaired. \\
\hline 42 & Genital markings on 13: (0) none; (1) paired; (2) unpaired. \\
\hline 43 & Genital markings on 14: (0) none; (1) paired; (2) unpaired. \\
\hline 44 & Genital markings on 15: (0) none; (1) paired; (2) unpaired. \\
\hline 45 & Genital markings on 16: (0) none; (1) paired; (2) unpaired. \\
\hline 46 & Genital markings on 17: (0) none; (1) paired; (2) unpaired. \\
\hline 47 & Genital markings on 18: (0) none; (1) paired; (2) unpaired. \\
\hline 48 & Genital markings on 19: (0) none; (1) paired; (2) unpaired. \\
\hline 49 & Genital markings on 20: (0) none; (1) paired; (2) unpaired. \\
\hline 50 & Genital markings on 21: (0) none; (1) paired; (2) unpaired. \\
\hline 51 & Genital markings on 22: (0) none; (1) paired; (2) unpaired. \\
\hline 52 & Genital markings on 23: (0) none; (1) paired; (2) unpaired. \\
\hline 53 & Genital markings on 24: (0) none; (1) paired; (2) unpaired. \\
\hline 54 & Genital markings on 25: (0) none; (1) paired; (2) unpaired. \\
\hline 55 & Genital markings on 26: (0) none; (1) paired; (2) unpaired. \\
\hline 56 & Genital markings on 27: (0) none; (1) paired; (2) unpaired. \\
\hline 57 & Genital markings on 28: (0) none; (1) paired; (2) unpaired. \\
\hline 58 & Genital markings on 29: (0) none; (1) paired; (2) unpaired. \\
\hline 59 & $\begin{array}{l}\text { First dorsal pore location: (0) not visible; (1) intersegment } 3 / 4 \text {; (2) } \\
\text { intersegment } 4 / 5 ;(3) \text { intersegment } 5 / 6 ;(4) \text { intersegment } 10 / 11 \text {; }(5) \\
\text { intersegment } 11 / 12 ;(6) \text { intersegment } 12 / 13 ; \text { (7) intersegment } 13 / 14 \text {. }\end{array}$ \\
\hline 60 & $\begin{array}{l}\text { Origin of intestine: (0) seg } 14 ; \text { (1) seg } 15 ; \text { (2) seg } 16 ; \text { (3) seg } 17 ; \text { (4) seg } \\
18 ;(5) \text { seg } 19 .\end{array}$ \\
\hline
\end{tabular}

Two coupled programs were used in the parsimony analysis. WINCLADA VER. 1.00.08 (Nixon, 2002) was used for constructing, editing, and storing the metadata. All binary characters were treated as additive, and multistate character state as non-additive. The matrix was spawned to NONA ver. 2.0 (Goloboff, 1993). The most parsimonious tree was established using a heuristic tree search with 100 replications (10 trees held/replication) via the multiple tree bisection reconnection (multiple TBR + TBR) search strategy. Support for the tree branches was calculated by a bootstrapping technique using 100 replications. The most parsimonious tree was selected based on the following criteria: the shortest tree length with the highest consistency and retention index. 


\section{RESULTS AND DISCUSSION}

\section{Variability within and among Populations of Earthworms}

Results of PCA analysis showed that the earthworms could be separated along the first two component axes (Figure 1). Of the 60 characters used to discriminate the earthworms from the different populations, only 29 were observed to significantly contribute to the differences. Five groups can be identified from six different sites in Burnay, Gitagum in Misamis Oriental and Manresa Farm, Cagayan de Oro City. Component 1 separates groups 1, 2, 3 and 4 from group 5 except for the 5 samples of group 4.

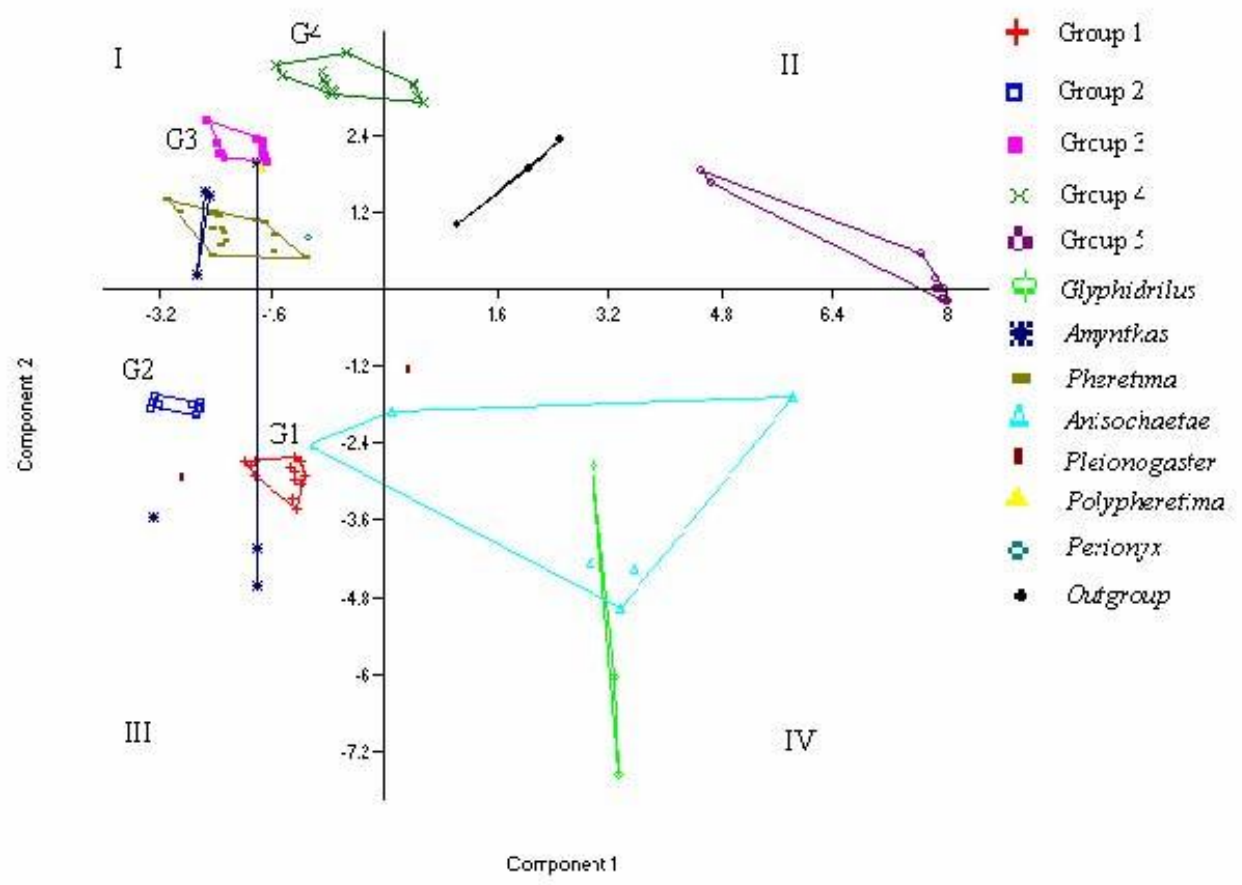

Fig. 1: Scatter plot of principal component analysis for 175 earthworm samples.

The observed differences concerns the following characters: megascolecine prostates, prostatic gland shape, last heart location, meroic nephridia, setal arrangement, pre-testicular spermathecae, location of gizzard, setae between male pore, presence of dorsal pore and first dorsal pore location, clitellum cover, presence of spermathecal pore, spermathecal pore location, and presence of paired female pore. Group 4 earthworms were unique in the positions of the spermathecal and first dorsal pores. Component 2 shows differentiation among the groups 1,2, 3 and 4 earthworms based on the following characters: presence of prostatic gland, paired or unpaired posteriormost spermathecal pores, presence of genital markings, paired or unpaired posteriormost genital markings, body pigmentation, prostomium type,and spermathecae on 6/7/8. Component 3 differentiates groups 1 and 4 from groups 2 and 3 based on the following characteristics: presence of male pore posterior to segment 16 , location of male pore, presence of gizzard, caeca and copulatory pouches, clitellum origin, clitellum shape, spermathecae on 8/9 and origin of intestine.

Descriptions of Earthworm Groups in PCA

Except for group 5 that is separated by component 1 in PCA, the earthworms in groups 1, 2, 3 and 4 belong to family Megascolecidae and have the following 
characteristics in common: 1) megascolecine type of prostatic gland, that is described as having gland openings combined with male pores on segment xviii; 2) possessing racemose kind of prostates; 3 ) all have male pores located on segment xviii; 4) the last pair of heart is located posterior to segment xi; 5) meroic nephridia, that is having small but numerous nephrons. Those without visible nephridia are construed as meroic: 6) the perichaetine type of setal arrangement, that is having unpaired and more than eight setae per segment that is equally distributed; and 7) having pretesticular spermathecae; 8) clitellum covering 2 to 3 segments; 9) gizzard on segment viii; 10) absence or presence of setae between male pores; 11) presence of dorsal pore; 12) location of first dorsal pore on intersegment 12/13.

\section{Group 1 (Fig. 2)}

These earthworms are limicolous, body pink in color (live) and are cylindrical 110 $\mathrm{mm}$ to $181 \mathrm{~mm}$ long and $3 \mathrm{~mm}$ to $4 \mathrm{~mm}$ wide. Number of segments ranges from 99 to 195 . [External Diagnostic Characters] Dorsal pores mostly found on 12/13 but some on 13/14; setae numerous and arranged separately on vii \& $\mathrm{xx}$ (perichaetinous); number of setae between male pore 6-8; clitellum annular, pale pink on segment xiv-xv, width $2.5-4 \mathrm{~mm}$; prostomium zygolobic; female gonopore not visible; paired male pores on segment xviii; 3 pairs of genital markings on segments xix-xxi and unpaired on xxii, or paired on segments xvii-xx and unpaired on xxi; spermathecal pores not visible. [Internal Diagnostic Characters] Origin of oesophagus mostly on segment xi, to some on xii or xiv and reaches to segment xvi or xv; 3 pairs of hearts on xii-xiv; number of gizzard 1 on segment ix; origin of intestine on xvi or xvii; vas deferens on xi-xvii, xi-xviii, xii-xvii and xii-xviii; caecum not visible; ovaries not visible; testes shiny on xi-xii; 2 pairs of seminal vesicles on xi-xii or xii-xiii. [Autapomorphic Characterstics of this earthworm] Clitellum covers 2 segments from segment xiv-xv, 3 pairs of genital markings similar to group 2 earthworms. There is only one unpaired genital marking on the most posterior region located either on segment xxi or xxii. Female gonopore and spermathecal pores are not visible, and origin of intestine is at segment xvi.

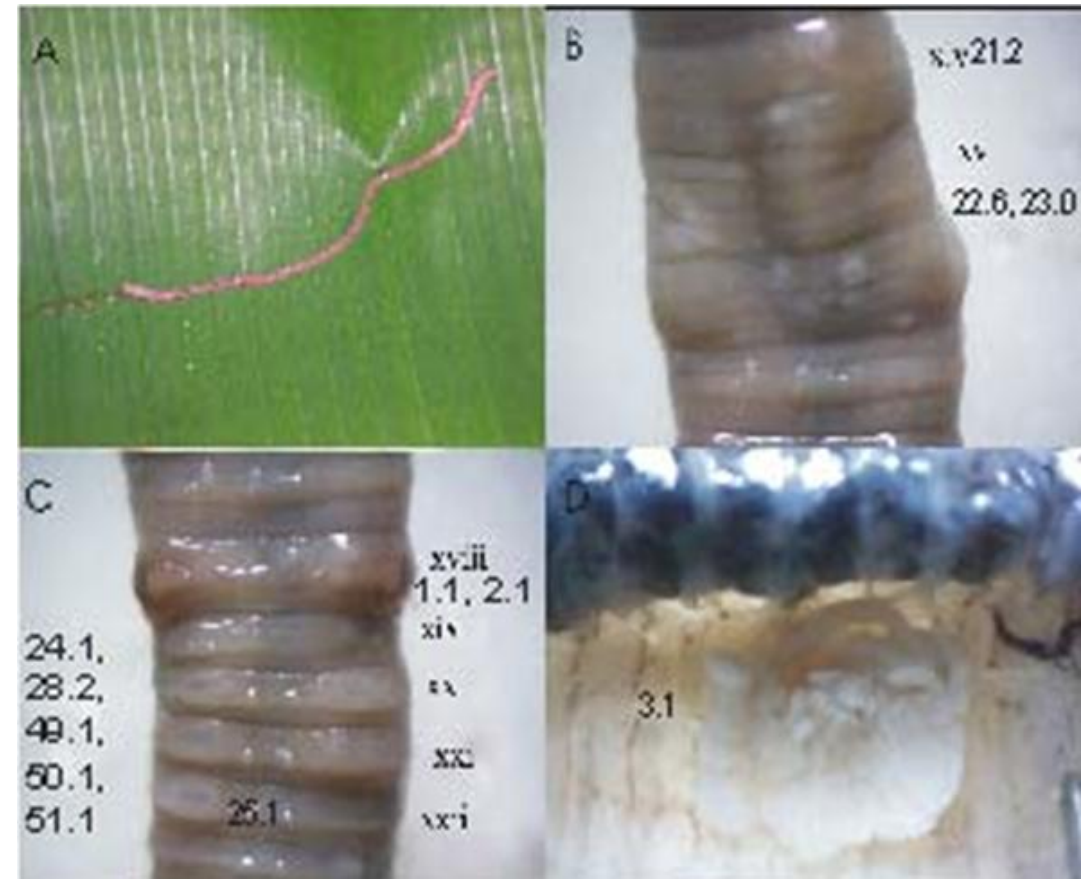

Fig. 2: Group 1 earthworms. A. adult specimen; B. clitellum cover with barely visible female gonopore; C. paired male gonopore at xviii with paired genital markings at xix, xx, xxi and unpaired at xxii; D. racemose prostate. 


\section{Group 2 (Fig. 3)}

These earthworms' bodies are pink in color, cylindrical in shape, 188-229 mm long and 4-5 mm wide. Number of segments ranges from 202 to 251.[External Diagnostic Characters] Dorsal pores on 12/13 and some on 13/14; setae numerous and arranged separately on vii \& xx (perichaetinous); setae between male pores $7-8$; clitellum annular, pale pink on segment xiv-xvi, width $2.5-4.5 \mathrm{~mm}$; prostomium zygolobic; single female gonopore on segment xiv; paired male gonopores on segment xviii; 3 pairs of genital markings on xix-xxi or xviii-xx; paired spermathecal pores present on 5/6. [Internal Diagnostic Characters] Origin of oesophagus on xi or xii, range 4 to 6 segments; hearts on xi-xiv or xii-xiv; number of gizzard 1 on $x$; origin of intestine on xvi or xvii; vas deferens on xi-xvii, xi-xviii, xii-xviii; caecum not visible; ovaries on xiii; location of testes on xi-xii; 2 pairs of seminal vesicles on xi-xii or xii-xiii. [Autapomorphic Characterstics of this earthworm] These earthworms have one pair of spermathecae on intersegment $5 / 6$, paired genital markings including the most posterior genital marks on segment xix-xxi or xviii-xx. They have 3 pairs of genital marks like the group 1 earthworms.

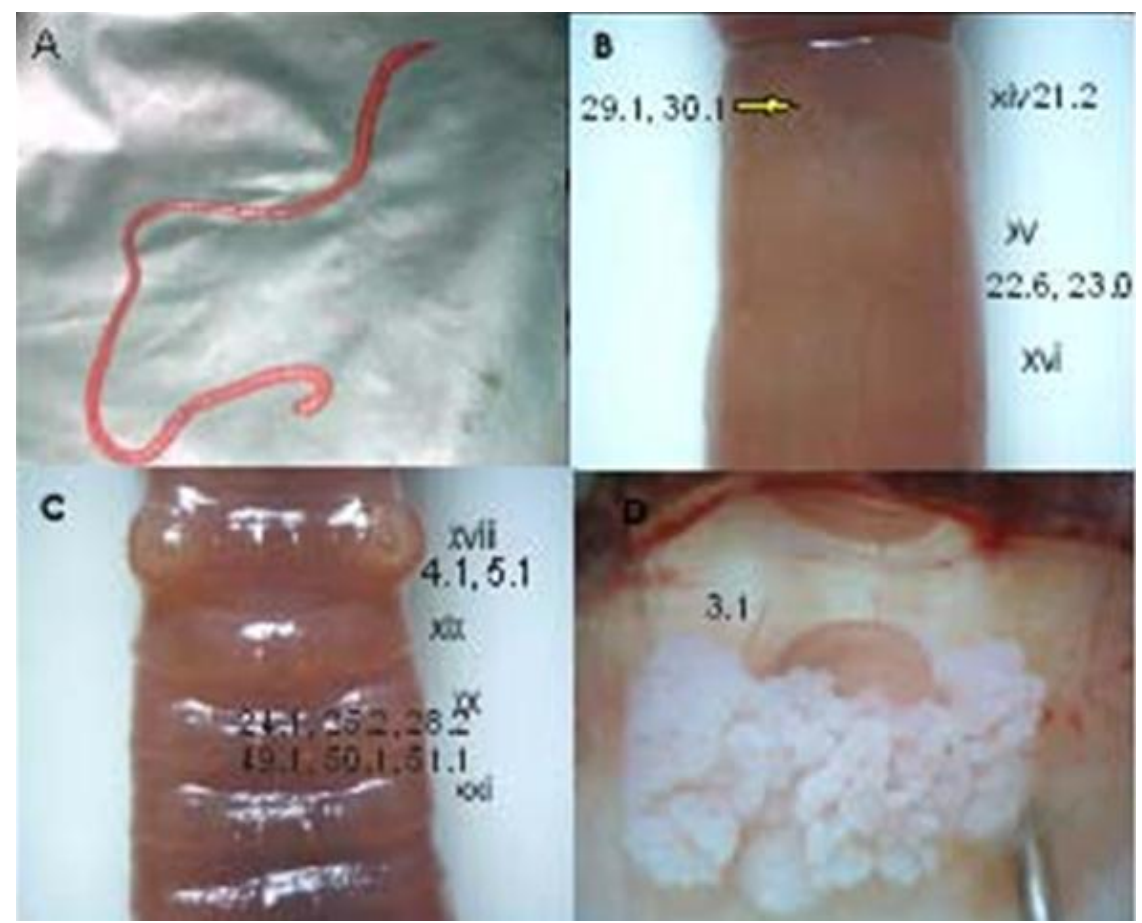

Fig. 3: Group 2 earthworms. A. the adult stage; B. clitellum cover with barely visible female gonopore; C. paired male gonopore at xviii with genital markings at xix, $\mathrm{xx}$ and $\mathrm{xxi}$; D. racemose prostate.

\section{Group 3 (Fig. 4)}

This group of earthworms has a distinct dark brown coloration; body iridescent and more pigmented on the dorsal part. Body is cylindrical 114-256 mm long and 6-9 mm wide on segment x. Number of segments ranges from 74 to 139. [External Diagnostic Characters] Dorsal pores on $12 / 13$ or $13 / 14$; setae numerous and separate on segments vii \& $\mathrm{xx}$; number of setae between male pore 6 to 8; clitellum annular, light brown on segments xiv - xvi, width 6-9 $\mathrm{mm}$; prostomium epilobic; single female gonopore on segment xiv; paired male gonopores on xviii; genital markings not visible; 3 pairs of spermathecal pores on 5/6/7/8 or 6/7. [Internal Diagnostic Characters] Origin of oesophagus vary from $\mathrm{x}$ to xii and reaches to segment either on xiv, $\mathrm{xv}$ or $\mathrm{xvi} ; 3$ pairs of hearts varying from segment xi-xiii to xii-xiv; single gizzard either on ix; origin of intestine either on xvi or xvii; vas deferens either on xixvii, xi-xviii or xii-xviii; caeca extending either from xiv-xx, xvi-xxiii, xvii-xxii or xviii-xxiii; 
location of ovaries on xiii; location of testes on xi-xii; 2 pairs of seminal vesicles either on xixii or xii-xiii. [Autapomorphic Characterstics] Three pairs of spermaticae on intersegments $5 / 6 / 7 / 8$. Origin of intestine on segment xiv.

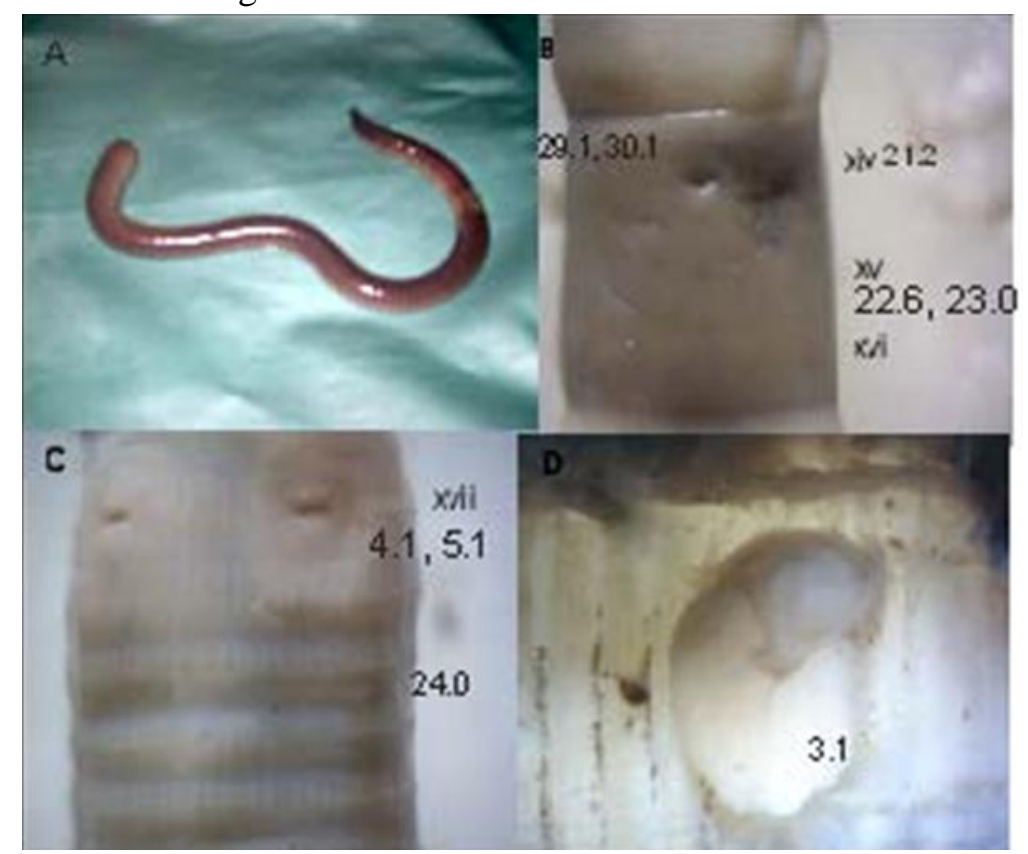

Fig. 4: Group 3 earthworms. A. Adult earthworm; B. clitellum cover with the female gonopore at xiv, C. paired male gonopore at $\mathrm{xviii}$; D. racemose prostate.

\section{Group 4 (Fig. 5)}

These earthworms are light brown in color with cylindrical bodies, 48-69 mm long, 2$4 \mathrm{~mm}$ wide. Number of segments range from 95 to 111. [External Diagnostic Characters] Dorsal pores on 10/11,12/13, 13/14; numerous setae arranged separately on segments vii and $\mathrm{xx}$ (perichaetinous); number of setae between male pores 7; Clitellum annular, pinkish on segment xiv-xvi or xv-xvii, width 2-3 mm; prostomium epilobic; single female pore on segment xiv; paired male pores on xviii; no genital markings; paired spermathecal pores on $5 / 6 / 7$ or 6/7/8/9 or 6/7/8. [Internal Diagnostic Characters] Origin of oesophagus on xi and reaches to xiii or $\mathrm{xv}$; hearts on segments ix to xi; 1 gizzard on vii or viii; origin of intestine vary from xiv to xvi; vas deferens on xi-xviii; caeca cover from xxi - xxviii; ovaries on xiii; testes on xi; 2 pairs of seminal vesicles on xi-xii. [Autapomorphic Characteristics] There are two pairs of spermathecae located on intersegments 5/6/7.

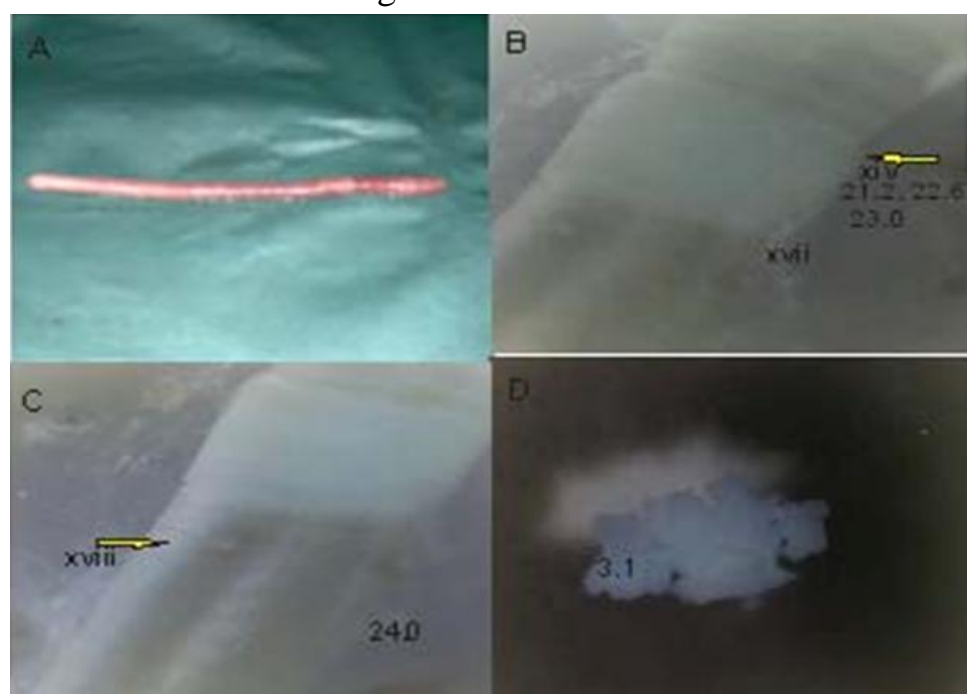

Fig. 5: Group 4 earthworms. A. adult earthworm, B. clitellum cover, female gonopore at xiv not clearly visible; C. paired male gonopore at xviii; D. racemose prostate. 


\section{Group 5 (Fig. 6)}

These are reddish purple in color (live specimen), shiny and somewhat flattened at the ventral posterior part. Body is 128-150 mm long, and 3.5-4 mm wide. Number of segments ranges from 129 to $150 \mathrm{~mm}$. [External Diagnostic Characters] Dorsal pore not visible; paired setae on vii and xx; clitellum annular, pale brown either on segments xiv-xvii or xiv-xviii, width 3-4 mm; prostomium tanylobic; single female gonopore on xiv; paired male gonopore on 17; genital markings not visible; spermathecal pores not visible. [Internal Diagnostic Characters] Origin of oesophagus on ix and reaches to either xi, xiii, or xvi; hearts either on ix-xi or ix-xii; 1 soft gizzard on segment vi; origin of intestine either on xiv, xvii or xvi; vas deferens on either $\mathrm{x}$ $\mathrm{xvii}$ or $\mathrm{x}$-xviii; ovaries on xiii; testes on xi; 2 pairs of seminal vesicles on $\mathrm{x}$ and $\mathrm{xii}$. [Autapomorphic Characters] This group has tubular and acanthodriline prostates, and lumbricine setae that is quiet different from the other three groups. Spermathecae are not visible and the clitellum covers 4 segments.

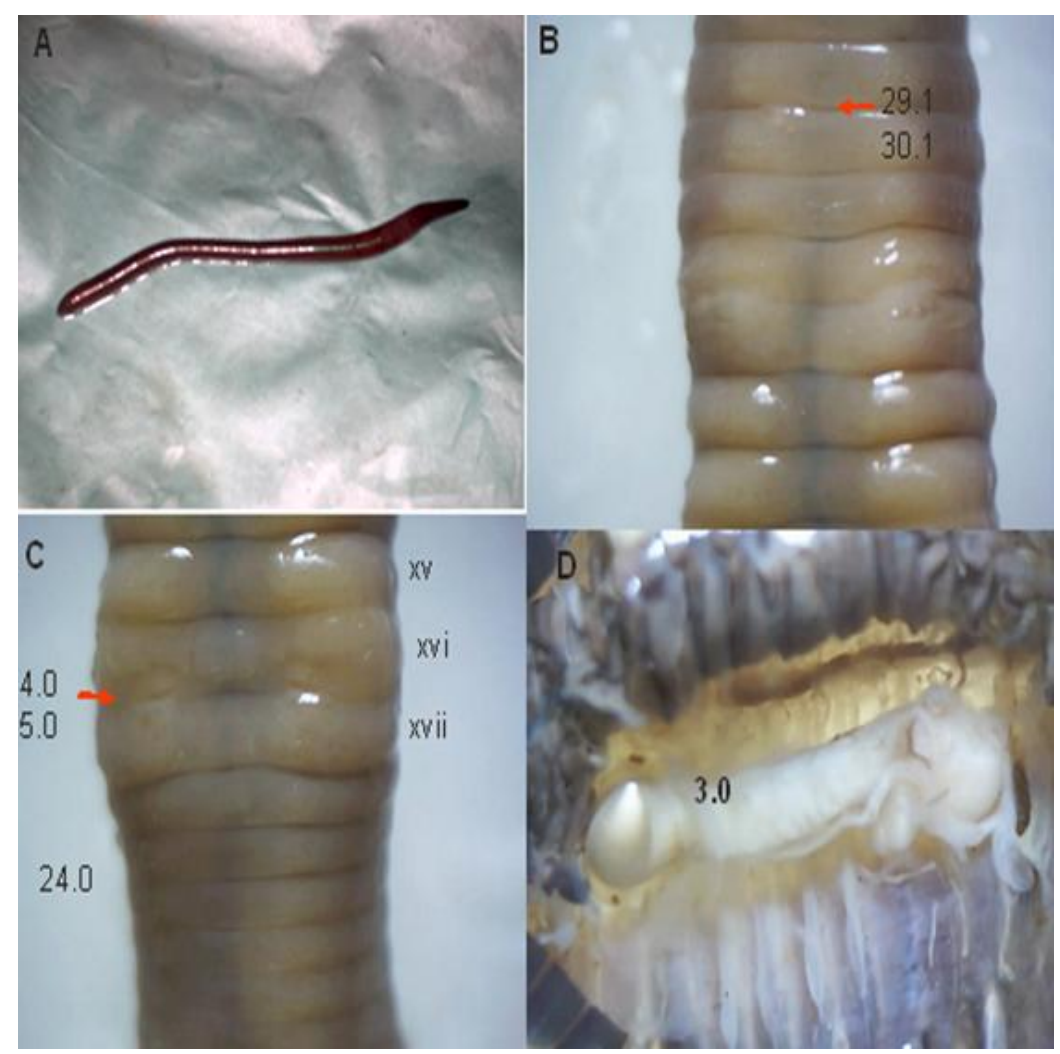

Fig. 6: Group 5 earthworms. A. adult specimen; B. clitellum cover, female gonopore at xviii; D. tubular and digitiform prostate.

Parsimony analysis of the data matrix revealed that the group 5 earthworms are more related to the outgroup $M$. dubius than the other populations of earthworms owing to a large number of pleisiomorphic characters present in this earthworm. The outgroup that belong to families Acanthodrilidae, Microchaetidae, and Octochaetidae including samples tagged as group 5 were clearly separated from Megascolecidae and from groups 1, 2, 3 and 4 in the cladogram (Figure 7). This result is in consonance with the separation of the earthworm population along the first principal component axis (Figure 1). Group 5 earthworms that are found at the basal part of the phylogram, have holoic nephridia, tubular prostates with acanthodriline type of opening similar to $M$. dubius. However, the tubular prostate in group 5 is more enlarged and digitiform 
rather than coiled typical of Acanthodrilidae. However, the characters possessed by group 5 are keyed to family Eudrilidae (Blakemore, 2006). The cladogram supports this contention but it cannot be identified as Eudrilus euginae because it differs from it in a number of characters as shown in table (1). Group 5 probably is a new species under Eudrilus.

Groups 1, 2, 3, and 4 are found to be members of the family Megascolecidae defined by megascolecine type of setae, meroic nephridia, and racemose prostates with megascolecine type of opening. Each of these groups has wide phenetic distances and showed no overlaps in character distribution in the PCA scatter plot.

The pattern and distribution of each group in the PCA scatter plot suggests that these earthworms might belong to new genera in the family Megascolecidae. These earthworms have characteristic features different from those of the genera Pheretima, Polypheretima, Pithemera, Planapheretima, Metaphire, Metapheretima, and Amynthas.

Table 2: Comparison between group 5 and Eudrilus euginae Perrier from Brisbane, Australia (Blakemore, 1994).

\begin{tabular}{|c|c|c|}
\hline & SPECIES GROUP 5 & E.euginae \\
\hline CHARACTERS & Vermicompost Area, Manresa Farm & Worm Farm, Brisbane, Australia \\
\hline 27) Number of Unpaired GM & none & ( \\
\hline 28) Number of GM pairs & none & none \\
\hline 31) Body pigmentation & pigmented & pigmented \\
\hline 32) Prostomium type & tanylobic & epilobic \\
\hline 33-37) Spermathecal Pore location & not visible & paired lateral, presetal on xiv \\
\hline 38-59) GM location & none & segments xvii and xviii \\
\hline 60) first dorsal pore & not visible & none \\
\hline \multicolumn{3}{|l|}{ Other Characters } \\
\hline Color & reddish purple & $\begin{array}{l}\text { red brown dorsum, anterior bright blue/green, } \\
\text { iridescent, ventrum beige }\end{array}$ \\
\hline Length & 128 to $150 \mathrm{~mm}$ & 115 to $165 \mathrm{~mm}$ \\
\hline Number of segments & 129 to 150 & 161 to 203 \\
\hline $\begin{array}{l}\text { Number of male } \\
\text { pore setae }\end{array}$ & none & none \\
\hline Range of oesophagous & segment xix to xvi & Data not available \\
\hline
\end{tabular}

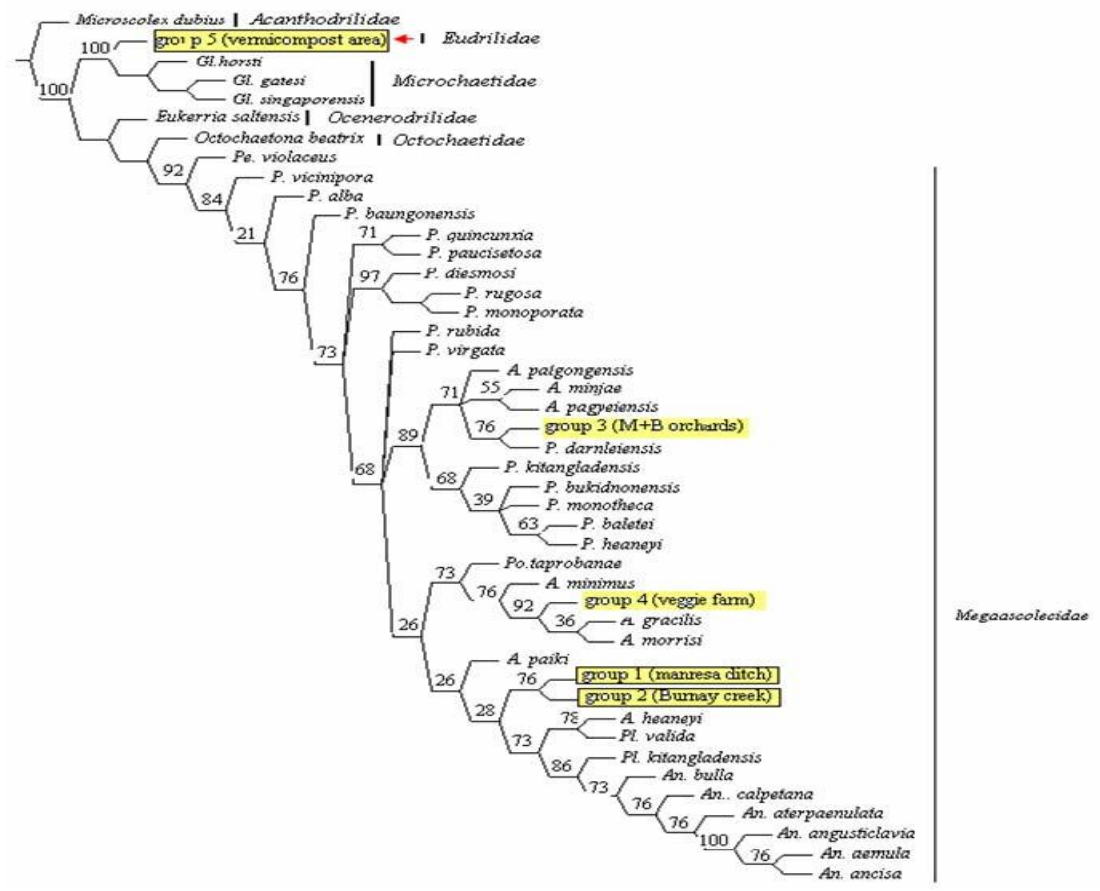

Fig. 7: Strict consensus of equally parsimonious trees from analysis of 60 characters for 45 species. 


\section{CONCLUSION}

This study used principal component and parsimony analyses to describe variations and groupings in earthworm individuals collected from selected populations in Mindanao, Philippines. Four groups were identified to belong to family Megascolecidae, and one group to family Eudrilidae based on observed differences in the number and pattern of genital markings, prostomium type, and the number and location of spermathecae. None of the four new megascolecid groups completely matches with the nearest genera of Oriental megascolecids. The results of the study showed that principal component analysis and parsimony analysis help clearly to describe and to indicate the existence of new species of earthworms.

\section{ACKNOWLEDGEMENT}

The senior author would like to acknowledge the administration of Xavier University, Cagayan de Oro City, Philippines for the faculty development program and the Commission of Higher Education (CHED) for the study grant.

\section{REFERENCES}

Beddard, F. E. (1912). Earthworms and their Allies. The Cambridge Manuals of Science and Literature. Cambridge University Press. London. pp. 1-153.

Benham, W. (1946). Studies in Earthworm XLII: The occurrence of the Genus Pheretima in New Zealand. Transaction of the Royal Society of New Zealand Vol.76, Part 3, pp.423-428.

Blakemore, R.J. (1994). Earthworms of Southeast Queensland and their Agronomic Potential in Brigalow Soils. Doctoral Dissertation. Australia: University of Queensland.

Blakemore, R. J. (2000). Tasmanian Earthworms. VermEcology, Canberra, Australia. pp. $1-800$.

Blakemore, R.J. (2007). Updated Checklist of Pheretimoids (Oligochaeta: Megascolecidae: Pheretima auct). COE Soil Ecology Research Group, Yokohama National University, Japan. Online. 3 March 2008. http://bioeco.eis.ynu.ac.jp/eng/database/earthworm/.

Bouchard, R.W. Jr., D. Huggins and James Kriz (2005). A Review of the Issues Related to Taxonomic Resolution in Biological Monitoring of Aquatic Ecosystems with an Emphasis on Macroinvertebrates. USEPA Report. pp. 1-38. http://www.kbs.ku.edu/larc/tech/assets/KBSRept133_TaxResol.pdf.

Goloboff, P. (1993). Nona. Software and Documentation by the Author. Tucuman, Argentina.

James, S.W. (2004). New Species of Amynthas, Pheretima, and Pleionogaster (Clitellata: Megascolecidae) of the Mt. Kitanglad Range, Mindanao Island, Philippines. The Raffles Bulletin of Zoology, 52(2): 289-313.

Miller, J.Z. (1999). On the Phylogenetic Relationships of Sisicottus hibernus (Araneae, Linyphiidae, Erigoninae). The Journal of Arachnology, 27(1): 44-52.

Nixon, K. C. (2002). WinClada (BETA) ver.0.9.99. Published by the Author, Ithaca, New York, USA. 